JPdK Volume 3 Nomor 2 Tahun 2021 Halaman 42-49

JURNAL PENDIDIKAN dan KONSELING

Research \& Learning in Primary Education

\title{
Reaktulisasi Pendidikan Kewarganegaraan bagi Generasi Milenial
}

\author{
Salsa Berliana Putri ${ }^{1}$, Dinie Anggaraeni Dewi ${ }^{2}$ \\ Program Studi Pendidikan Guru Sekolah Dasar \\ Fakultas Keguruan dan Ilmu Pendidikan \\ Universitas Pendidikan Indonesia \\ Email: salsaberliana@upi.edu ${ }^{1}$, dinieanggaraenidewi@upi.edu²
}

\begin{abstract}
Abstrak
Pendidikan kewarganegaraan bagi suatu negara-bangsa merupakan proses pembinaan, penanaman, dan pewarisan nilai-nilai kebangsaan dan kenegaraan yang diselenggarakan dalam lingkungan pendidikan, karena pendidikan dipandang memiliki peranan penting dan strategi dalam pembangunan bangsa. Dalam perkembangannya di Indonesia, Pendidikan Kewarganegaraan mengalami perubahan dan penyempurnaan sejak zaman Orde Lama (1950-1966), Orde Baru (1966-1998), dan Orde Reformasi (1998-sekarang). Artikel ini membicarakan pentingnya dilakukan reaktualisasi dalam Pendidikan Kewarganegaraan bagi generasi milenial. Pendidikan Kewarganegaraan dirumuskan secara luas mencakup proses penyiapan generasi muda guna mengambil peran dan tanggung jawabnya sebagai warga negara, dan secara khusus, peran pendidikan termasuk di dalamnya sekolah, pengajaran dan belajar, dalam proses penyiapan warga negara tersebut. Generasi milenial sebagai bagian dari anak bangsa Indonesia diharapkan dapat memahami pendidikan kewarganegaraan dan menjadi warga negara yang memiliki komitmen yang kuat dan konsisten untuk mempertahankan Negara Kesatuan Republik Indonesia (NKRI). Karena Hakikat negara kesatuan Republik Indonesia adalah negara kebangsaan modern. Negara kebangsaan modern adalah negara yang pembentukannya didasarkan pada semangat kebangsaan atau nasionalisme yaitu pada tekad suatu masyarakat untuk membangun masa depan bersama di bawah satu negara yang sama, walaupun warga masyarakat tersebut berbeda-beda agama, ras, etnik, atau golongannya.
\end{abstract}

\section{Kata Kunci: Reaktualisasi, Pkn, Generasi Milenial}

\begin{abstract}
Citizenship education for a nation-state is a process of fostering, cultivating and inheriting national and national values which are held in an educational environment, because education is seen as having an important role and strategy in nation building. During its development in Indonesia, Citizenship Education has undergone changes and improvements since the Old Order (1950-1966), New Order (1966-1998), and the Reform Order (1998-present). This article discusses the importance of re-actualizing Citizenship Education for the millennial generation. Citizenship education is broadly formulated to include the process of preparing young people to take on their roles and responsibilities as citizens, and in particular, the role of education, including schools, teaching and learning, in the process of preparing these citizens. It is hoped that the millennial generation as part of the Indonesian nation's children can understand citizenship education and become citizens who have a strong and consistent commitment to defending the Unitary State of the Republic of Indonesia (NKRI). Because the essence of the unitary state of the Republic of Indonesia is a modern nation state. The modern nation-state is a state whose formation is based on the spirit of nationality or nationalism, namely on the determination of a society to build a common future under the same state, even though the citizens of that community are of different religions, races, ethnicities, or groups.
\end{abstract}

Keywords: Reactualization, Pkn, Millennial Generation

\section{PENDAHULUAN}


Kata kewarganegaraan dalam bahasa Latin disebut Civicus. Selanjutnya, kata Civicus diserap ke dalam bahasa Inggris menjadi kata Civic yang artinya mengenai warga negara atau kewarganegaraan. Dari kata Civic lahir kata Civic yaitu ilmu kewarganegaraan, dan Civic Education, yaitu Pendidikan Kewarganegaraan. Pelajaran Civics atau kewarganegaraan telah dikenal di Indonesia sejak zaman kolonial Belanda dengan nama Burgerkunde. Tujuan Pendidikan Kewarganegaraan sebagai sesuatu yang tak terpisahkan dalam membangun bangsa, adalah:

a. Mencerdaskan kehidupan bangsa yang mengembangkan manusia Indonesia seutuhnya. yaitu manusia yang beriman dan bertakwa kepada Tuhan Yang Maha Esa dan berbudi pekerti yang luhur, memiliki kemampuan pengetahuann dan keterampilan, kesehatan jasmani dan rohani, kepribadian mantap dan mandiri serta rasa tanggung jawab kemasyarakatan dan kebangsaan". Mampu Memahami dan menguasai secara nalar konsep dan norma Pancasila sebagai Humaidi, Revitalisasi Pendidikan... 142 falsafah, dasar ideologi dan pandangan hidup Negara kesatuan republik Indonesia (NKRI). Memahami secara langsung apa itu konstitusi (UUD RI 1945) dan hukum yang berlaku dalam Negara RI. Menghayati dan meyakini tatanan dalam moral yang termuat dalam butir diatas. Mengamalkan dan membakukan hal-hal diatas sebagai sikap perilaku diri dan kehidupannya dengan penuh keyakinan dan nalar.

b. Secara khusus. Tujuan PKn yaitu membina moral yang diharapkan diwujudkan dalam kehidupan sehari-hari yaitu perilaku yang memancarkan iman dan takwa terhadap Tuhan Yang Maha Esa dalam masyarakat yang terdiri dari berbagai golongan agama, perilaku yang bersifat kemanusiaan yang adil dan beradab, perilaku yang mendukung kerakyatan yang mengutamakan kepentingan bersama diatas kepentingan perseorangan dan golongan sehingga perbedaan pemikiran pendapat ataupun kepentingan diatasi melalui musyawarah mufakat, serta perilaku yang mendukung upaya untuk mewujudkan keadilan sosial seluruh rakyat Indonesia.1

c. Pendidikan Kewarganegaraan adalah : Partisipasi yang penuh nalar dan tanggung jawab dalam kehidupan politik dari warga negara yang taat kepada nilai-nilai dan prinsip-prinsip dasar demokrasi konstitusional Indonesia. Partisipasi warga negara yang efektif dan penuh tanggung jawab memerlukan penguasaan seperangkat ilmu pengetahuan dan keterampilan intelektual serta keterampilan untuk berperan serta. Partisipasi yang efektif dan bertanggung jawab itu pun ditingkatkan lebih lanjut melalui pengembangan disposisi atau watak-watak tertentu yang meningkatkan kemampuan individu yang berperan serta dalam proses politik dan mendukung berfungsinya sistem politik yang sehat serta perbaikan masyarakat.

d. Tujuan umum pelajaran PKn ialah mendidik warga negara agar menjadi warga negara yang baik, yang dapat dilukiskan dengan "warga negara yang patriotik, toleran, setia terhadap bangsa dan negara, beragama, demokratis, dan Pancasila sejati" Secara umum, tujuan negara mengembangkan Pendiddikan Kewarganegaraan agar setiap warga negara menjadi warga negara yang baik (to be good citizens), yakni warga negara yang memiliki kecerdasan (civics inteliegence) baik intelektual, emosional, sosial, maupun spiritual; memiliki rasa bangga dan tanggung jawab (civics responsibility); dan mampu berpartisipasi. Setelah menelaah pemahaman dari tujuan Pendidikan Kewarganegaraan, maka dapat disimpulkan bahwa Pendidikan Kewarganegaraan berorientasi pada penanaman konsep kenegaraan dan juga bersifat implementatif dalam kehidupan sehari - hari. Adapun harapan yang ingin dicapai setelah pengajaran Pendidikan Kewarganegaraan 
ini, akan didapatkan generasi milenial yang mampu menjaga keutuhan dan persatuan bangsa.

Jika demikian, lalu apa saja fungsi pendidikan kewarganegaraan? Fungsi pendidikan kewarganegaraan antara lain adalah:

a. Membantu generasi milenial untuk memperoleh pemahaman cita-cita nasional sebagai tujuan Negara.

b. Generasi milenial dapat mengambil keputusan-keputusan yang bertanggung jawab dalam menyelesaikan masalah pribadi, masyarakat dan negara.

c. Dapat mengapresiasikan cita-cita nasional dan dapat membuat keputusankeputusan yang cerdas.

\section{METODOLOGI PENELITIAN}

Jenis penelitian yang digunakan adalah penelitian deskriptif kualitatif. Waktu dan Tempat Penelitian Khususnya untuk penelitian kualitatif. Waktu dan tempat penelitian perlu dituliskan secara jelas (untuk penelitian kuantitatif, juga perlu sedangkan untuk kajian pustaka tidak perlu ada sub bab waktu dan tempat penelitian). Penelitian ini yakni mahasiswa Panca Marga yang mengikuti mata kuliah Pendidikan Kewarganegaraaan.

Penelitian ini dimulai dari observasi kondisi subjek, dan di lanjutkan dengan tinjauan pustaka dan pengambilan data, kemudian pada step terakir yakni analisis data dan pengambilan kesimpulan. Teknik pengumpulan data menggunakan observasi dan wawancara. Teknik pemeriksa keabsahan data yang digunakan adalah teknik triangulasi, yaitu teknik pemeriksaan keabsahan data yang memanfaatkan sesuatu yang lain di luar data untuk keperluan pengecekan atau sebagai pembanding terhadap data tersebut, Lexy J. Moleong (2000: 178). Teknik triangulasi yang digunakan dalam penelitian ini adalah triangulasi metode, yaitu dengan cara mengecek ulang informasi hasil wawancara dengan observasi. Teknik analisis data yang digunakan dalam penelitian ini terdiri dari 4 tahap yaitu 1). Utinisasi atau kategorisasi 2). Reduksi data 3). Display data 4). Penarikan kesimpulan.

Analisis data terdiri dari tiga alur kegiatan yang terjadi secara bersamaan, yaitu reduksi data, penyajian data, dan penarikan kesimpulan/verivikasi. Terjadi secara bersamaan berarti reduksi data, penyajian data, dan penarikan kesimpulan/verivikasi sebagai sesuatu yang saling jalin menjalin merupakan proses siklus dan interaksi pada saat sebelum, selama, dan sesudah pengumpulan data dalam bentuk sejajar yang membangun wawasan umum yang disebut "analisis"

Pendidikan Kewarganegaraan atau Civic Education adalah program pendidikan yang bersifat multifaket dengan konteks lintas bidang keilmuwan yang disebut interdisipliner dan multidimensional berlandaskan pada teoriteori disiplin ilmu-ilmu sosial, yang secara struktural bertumpu pada disiplin ilmu politik. Menurut Udin S. Winataputra (2008), sifat multi dimensional inilah membuat bidang kajian Pkn dapat disikapi sebagai; Pendidikan Kewarganegaraan, Pendidikan Politik, Pendidikan Nilai dan Moral, Pendidikan Karakter Kebangsaan, Pendidikan Kemasyarakatan, Pendidikan Hukum dan HAM serta Pendidikan Demokrasi. Menurut H. A. Kosasih Djahiri mengemukakan bahwa hakikat Pkn atau civic education adaah program pendidikan pembelajaran yang secara programatik-prosedural yang berupaya memanusiakan (humanizing) dan membudayakan (civilizing) serta memberdayakan (empowering) manusia/anak didik (diri dan kehidupannya) menjadi warga negara yang baik sebagaimana tuntutan keharusan/yurudis konstitusional bangsa/negara (Budimansyah : 2006).

Secara programatik materi ajar pendidikan kewarganegaraan secara utuh 
memberi bekal pengetahuan politik, hukum yang berlaku dalam masyarakat, berbangsa, dan bernegara. Mater ajar secara faktual teoritik konseptual dan normatif berisi pesan nilainilai moral serta aturan main dan cara pelaksanaannya. Program Pkn menitikberatkan pada pembentukan insan yang religius, demokratis, cerdas, terampil, dan sejahtera serta cinta bangsa dan bernegara serta mampu menjaga nama baik martabat bangsa dan negara dalam pergaulan antar bangsa-bangsa di dunia. Secara prosedural pembelajaran Pkn menyiapkan bahan ajar pilihan yang secara fungsional kearah pembinaan, pengembangan, dan pembentukan potensi diri anak didik baik dalam lingkugan fisik maupun nonfisik secara demokratis, humanis, dan fungsional.

\section{Visi dan Misi Pendidikan Kewarganegaraan}

Secara filosofis Pendidikan Kewarganegaraan memilki visi holistikeklektis yang memadukan secara serasi pandangan perenialisme, esensialisme, progresifisme, dan sosiorekonstruksionisme dalam konteks keindonesiaan. Secara sosiopolitik dan kultural pendidikan kewarganegaraan memiliki visi pendidikan untuk mencerdaskan kehidupan bangsa yakni menumbuhkembangkan kecerdasan kewarganegaraan (civic intelligence) merupakan prasyarat untuk pembangunan demokrasi dalam arti luas, yang mempersyaratkan terwujudnya kebudayaan kewarganegaraan atau civic culture sebagai salah satu determinan tumbuh-kembangnya negara demokrasi. Bertolak dari visinya tersebut, maka pendidikan kewarganegaraan mengemban misi mutidimensional, sebagai berikut:

a. Mengembangkan potensi peserta didik (misi psikopedagogis)

b. Menyiapkan peserta didik untuk hidup dan berkehidupan dalam masyarakat negara bangsa (misi psikososial) c. Membangun budaya kewarganegaraan sebagai salah satu detereminan kehidupan yang demokratis (misi sosiokultural)

\section{Tujuan Pendidikan Kewarganegaraan}

Secara holistik pendidikan kewarganegaraan bertujuan agar setiap warga negara muda (young citizens) memiliki rasa kebangsaan dan cinta tanah air dalam konteks nilai dan moral Pancasila, nilai dan norma Undang-Undang Dasar Negara Republik Indonesia Tahun 1945, nilai dan komitmen Bhineka Tunggal Ika, dan komitmen bernegara kesatuan Republik Indonesia. Oleh karena itu secara sadar dan terencana peserta didik sesuai dengan perkembangan dan psikologis dan konteks kehidupannya secara sistemik difasilitasi untuk belajar berkehidupan demokrasi secara utuh, yakni belajar tentang demokarsi (learning about democracy), belajar dalam iklim dan melalui proses demokrasi (learning through democracy) dan belajar untuk membangun demokarsi (learning for democracy).

\section{Landasan Pendidikan Kewarganegaraan}

UUD 1945 sebagai landasan Konstitusional pada bagian Pembukaan alinea keempat memberikan dasar pemikiran tentang tujuan negara. Salah satu tujuan negara tersebut dapat dikemukakan dari pernyataan 'mencerdaskan kehidupan bangsa'. Apabila dikaji maka tiga kata ini mengandung makna yang cukup dalam. Mencerdaskan kehidupan bangsa mengandung pesan pentingnya pendidikan pendidikan bagi seluruh anak bangsa. Dalam kehidupan berkewarganegaraan, pernyataan ini memberikan pesan kepada penyelenggara negara dan segenap rakyat agar memilki kemampuan dalam berpikir, bersikap, dan berperilaku serta cerdas baik dalam proses pemecahan masalah maupun dalam 
pengambilan keputuan kenegaraan kebangsaan, dan kemasyarakatan.

UU Nomor 20 Tahun 2003 tentang Sisdiknas sebagai landasan operasional dan pesan yang terkait dengan pendidikan kewarganegaraan. Pada Pasal 3 ayat (2) tentang fungsi dan tujuan negara dikemukan bahwa: Pendidikan nasional berfungsi mengembangkan dan membentuk watak serta peradaban bangsa yang martabat dalam rangka mencerdaskan kehidupan bangsa, bertujuan untuk berkembangnya potensi peserta didik agar menjadi manusia yang beriman dan bertakwa kepada Tuhan Yang Maha Esa, berakhlak mulia, sehat, berilmu, cakap, kreatif, mandiri, yang menjadi warga negara yang demokratis serta bertanggung jawab.

\section{HASIL PENELITIAN DAN PEMBAHASAN}

Berdasarkan hasil yang diperoleh dalam penelitian mengenai Reaktualisasi Pendidikan Kewarganegaraan Bagi Generasi Milenial yaitu sebagai berikut: Reaktualisasi atau mengembalikan pentingnya Pendidikan Kewarganegaraan bagi generasi milenial merupakan usaha para pakar pendidikan dalam upaya menghadirkan kembali generasi yang kuat, kokoh dan konsisten dengan Pancasila dan UUD 1945. Pemilihan Mata Pelajaran Pendidikan Kewarganegaraan bukan sesuatu yang kebetulan, melainkan merupakan mata pelajaran yang memfokuskan pada pembentukan warga negara yang memahami dan mampu melaksanakan hak-hak dan kewajibannya untuk menjadi warganegara Indonesia yang cerdas, terampil, dan berkarakter yang diamanatkan oleh Pancasila dan UUD 1945.

Dengan mempelajari Pendidikan Kewarganegaraan generasi milenial memiliki kemampuan untuk berpikir secara kritis, rasional, dan kreatif dalam menanggapi isu kewarganegaraan juga dapat berpartisipasi secara aktif dan bertanggung jawab, dan bertindak secara cerdas dalam kegiatan bermasyarakat, berbangsa, dan bernegara, serta memahami pendidikan anti-korupsi. Selain itu diharapkan tumbuh dan berkembang secara positif dan demokratis pembentukan diri mereka berdasarkan karakter-karakter masyarakat Indonesia agar dapat hidup bersama dengan bangsa-bangsa lainnya, dan yang terpenting lagi adalah mereka dapat berinteraksi dengan bangsa-bangsa lain dalam percaturan dunia secara langsung atau tidak langsung dengan memanfaatkan teknologi informasi dan komunikasi.

Ruang lingkup mata pelajaran Pendidikan Kewarganegaraan yang dapat mendukung pembentukan generasi milenial yang kuat, tangguh dan konsisten meliputi aspek-aspek sebagai berikut. Pertama: Persatuan dan Kesatuan bangsa, meliputi: Hidup rukun dalam perbedaan, cinta lingkungan, kebanggaan sebagai bangsa Indonesia, sumpah pemuda, keutuhan Negara Kesatuan Republik Indonesia, partisipasi dalam pembelaan negara, sikap positif terhadap Negara Kesatuan Republik Indonesia, keterbukaan dan jaminan keadilan. Kedua: Norma, hukum dan peraturan, meliputi: tertib dalam kehidupan keluarga, tata tertib di sekolah, norma yang berlaku di masyarakat, peraturan-peraturan daerah, normanorma dalam kehidupan berbangsa dan bernegara, sistim hukum dan peradilan nasional, hukum dan peradilan internasional. Ketiga: Hak asasi manusia meliputi: hak dan kewajiban anak, hak dan kewajiban anggota masyarakat, instrumen nasional dan internasional HAM, pemajuan, penghormatan dan perlindungan HAM. Keempat: Kebutuhan warga negara meliputi: hidup gotong royong, harga diri sebagai warga masyarakat, kebebasan berorganisasi, kemerdekaan mengeluarkan pendapat, menghargai keputusan bersama, Prestasi diri , persamaan kedudukan warga negara. Kelima: Konstitusi Negara meliputi: Proklamasi kemerdekaan dan konstitusi yang pertama, konstitusi-konstitusi yang pernah digunakan di Indonesia, hubungan dasar negara dengan konstitusi. Pendidikan kewarganegaraan 
idealnya harus diketahui dan dipelajari oleh seluruh bangsa dan rakyat Indonesia terutama bagi generasi milenial. Mengapa Pendidikan Kewarganegaraan ini sangat penting bagi generasi milenial? Karena mereka akan:

a. Menjadi pribadi yang mengetahui akan hak serta kewajibannya sebagai warga Negara Indonesia. Dengan demikian generasi milenial dapat menjadi pelopor kehidupan berbangsa dan bernegara yang berkeadilan, berkemanusiaan, dan berdemokrasi.

b. Berpikir kritis mengenai isu nasional dan internasional. Diharapkan, generasi milenial menjadi agent of change atau agen pembaharu yang mendorong perubahan pendidikan,sosial, budaya dan ekonomi secara berkelanjutan.

c. Menjadi pribadi yang mempunyai toleransi tinggi dengan cara memahami budaya dan adat dari segala suku,bahasa,bangsa di Indonesia. Dengan begitu, generasi milenial bisa menjadi generasi penerus bangsa yang memiliki toleransi tinggi terhadap adat,suku,bahasa dan budaya yang plural dan majemuk.

d. Menjadi pribadi yang cinta damai.Dengan belajar bagaimana berdemokrasi yang baik dan benar diharapkan generasi milenial bisa menjadi sosok penerus bangsa yang demokratis dan cinta damai, sehingga tujuan demokrasi pancasila di Indonesia bisa tercapai.

e. Menjadi sosok yang mengenal dan berpartisipasi dalam memberi makna dalam kehidupan.

Komitmen yang kuat dan konsisten terhadap prinsip dan semangat kebangsaan dalam kehidupan bermasyarakat, berbangsa dan bernegara yang berdasarkan Pancasila dan Konstitusi Negara Indonesia perlu ditularkan secara terus menerus utnuk memberikan pemahaman yang mendalam tentang Negara Kesatuan Republik Indonesia. Secara historis, negara Indonesia telah diciptakan sebagai Negara Kesatuan Republik Indonesia. Negara Kesatuan Republik Indonesia adalah negara yang berkedaulatan rakyat dengan berdasar kepada Ketuhanan Yang Maha Esa, Kemanusiaan yang adil dan beradab, Persatuan Indonesia dan kerakyatan yang dipimpin oleh hikmat kebijaksanaan dalam permusyawaratan perwakilan, serta dengan mewujudkan keadilan sosial bagi seluruh rakyat Indonesia. (Pembukaan UUD Negara Republik Indonesia 1945).

Dalam perkembangannya selama 72 tahun Indonesia merdeka telah mengalami berbagai peristiwa yang mengancam persatuan dan kesatuan bangsa. Untuk itulah pemahaman yang mendalam dan komitmen yang kuat dan konsisten terhadap prinsip semangat kebangsaan dalam kehidupan bermasyarakat, berbangsa, dan bernegara yang berdasarkan pada Pancasila dan Konstitusi Negara Indonesia perlu ditanamkan kepada seluruh komponen bangsa Indonesia, khususnya generasi muda sebagai penerus bangsa.

Indonesia dimasa depan semakin baik kehidupan demokrasi dalam arti sistem pemerintahan semakin terjamin hak-hak warga negara untuk menjalankan prinisp demokrasi dalam kehidupan masyarakat, bangsa, dan negara. Kehidupan yag demokratis di dalam kehidupan sehari-hari dilingkungan keluarga, sekolah, masyarakat, pemerintah, dan organisasi non pemerintah perlu dikenal, dimulai, diinternalisasi, dan diterapkan demi kejayaan bangsa dan negara Indonesia. Demokrasi dalam suatu negara hanya akan tumbuh subur apabila dijaga oleh warga negara yang demokratis. Warga negara yang demokratis bukan hanya nenikmati hak kebebasan individu, tetapi juga harus memikul tanggung jawab secara bersama-sama dengan orang lain untuk membentuk masa depan yang cerah. Sesungguhnya, kehidupan yang 
demokratis adalah cita-cita yang dicerminkan dan diamanatkan oleh pendiri bangsa dan negara ketika mereka pertama kali membahas dan merumuskan Pancasila dan UUD 1945.

Inti dari kepribadian warga negara adalah kebijakan kewarganegaraan (civic virtues). Pengembangan kebijakan kewarganegaraan perlu ditopang dengan pengembangan elemenelemennya yakni: wawasan/pengetahuan kewarganegaraan (civic knowledge), sikap kewarganegaraan (civic disposition), keterampilan kenegaraan (civic skills), komitmen kenegaraan (civic commitment), kepercayaan diri kenegaraan (civic confidence), dan kecakapan kenegaraan (civic competence). Secara keseluruhan kebijakan kenegaraan tersebut sangat diperlukan oleh setiap orang agar mau dan mampu mewujudkan partisipasi kewarganegaraan secara cerdas dan bertanggung jawab (intelligent and responsible civic participation).

Berkenaan dengan hal-hal yang di uraikan di atas, pendidikan memiliki peranan dan tanggung jawab yang sangat penting dalam mempersiapkan warga negara yang memiliki komitmen kuat dan konsisten untuk mempertahankan Negara Kesatuan Republik Indonesia. Upaya yang dapat dilakukan adalah menyelenggarakan program pendidikan yang memberikan berbagai kemampuan sebagai seorang warga negara melalui mata pelajaran Pendidikan Kewarganegaraan (citizenship). Keluarga, tokoh-tokoh keagamaan dan kemasyarakatan, media massa, dan lembagalembaga lainnya yang bekerja sama dan memberikan kontribusi yang kondusif terhadap tanggung jawab pendidikan tersebut.

\section{Pendidikan Kewarganegaraan} (citizenship) merupakan mata kuliah yang memfokuskan pada pembentukan diri yang beragam dari segi agama, sosio-kultural, bahasa, usia, dan suku bangsa untuk menjadi warga negara Indoneisa yang cerdas, terampil, dan berkarakter yang dilandasi oleh Pancasila dan UUD 1945.

\section{SIMPULAN}

Pelajaran Pendidikan Kewarganegaraan dapat memiliki rasa kebangsaan dan cinta tabah air dengan memakai produk negaranya sendiri dan memelihara rasa persatuan dan kesatuan. Pendidikan Kewarganegaran bagi generasi milenial sebagai salah satu pilar penyangga dalam membangun karakter dan jati diri bangsa artinya bahwa pendidikan kewarganegaraan mendidik warga negara yang baik (good citizen), warga negara yang cerdas (smart citizen) dalam menghadapi perkembangan dunia di era kompetitif. Oleh sebab itu, pendidikan kewarganegaraan memberi bekal kepada warga negara terutama bagi generasi milenial baik itu kecerdasan intelektual, kecerdasan emosional, kecerdasan spiritual. Kecerdasan yang dimiliki seorang warga negara diharapkan dapat dimanfaatkan untuk berpikir dalam menganalisis dalam berbagai masalah.

\section{DAFTAR PUSTAKA}

Al-Muchtar, Suwarma. (2000). Pengantar Studi Sistem Politik Indonesia. Bandung: Gelar Pustaka Mandiri.

Asshiddiqie, Jimly. (2006). Kemerdekaan Berserikat, Pembubaran Partai Politik, dan Mahkamah Konstitusi. Jakarta: Konstitusi Press.

Azra, Azyumardi. (2006). Paradigma Baru Pendidikan Nasional: Rekonstruksi dan Demokratisasi. Jakarta: Penerbit Kompas.

Darmawan, A. B. dan C. (2017). Revitalisasi Paradigma Konservatif Pendidikan Demokrasi Pada Pkn Dengan Inovasi Media Pembelajaran. Jurnal Ilmiah Pendidikan Pancasila Dan Kewarganegaraan, 2(2).

Dasim. (2008). Pendidikan Nilai Moral dalam Dimensi Pendidikan Kewarganegaraan. Bandung: Laboratorium Pendidikan Kewarganegaraan FPIPS UPI [Fakultas Pendidikan Ilmu Pengetahuan Sosial Universitas Pendidikan Indonesia].

Cholisin. Materi pokok ilmu kewarganegaraan-pendidikan kewarganegaraan. Yogyakarta: UNY Press. 2007 
Kaelan. 2014. Pendidikan Pancasila. Yogyakarta: Paradigma. Lexy J. Moleong. 2000. Metode Kualitatif. Bandung: Remaja Rosda Karya.

Margaret S. (1999). Belajar Civic Education dari Amerika. Yogyakarta: Penerbit LKiS.

Soemantri, 2010. Internalisasi PKn dalam Pendidikan dan Pengajaran. Surabaya: PT. Alva Media. Oktober 2008

Wahyu Alfi, 2014. Generasi Muda- Generasi Penerus Bangsa. Jakarta: Piramida Press.
Komalasari, $\mathrm{K} \quad \& \quad$ syaifullah. Kewarganegaraan Indonesia konsep perkembangan dan masalah kontemporer. Bandung: Lab PKn UPI

Muchson. 2004. Etika Kewarganegaraan. Jakarta:Depdiknas

Winarno, Dwi. 2006. Paradigma Baru Pendidikan Kewarganegaraan, Bumi Aksara, Jakarta

Yusra, Dhoni (ed). 2006. Membangun Karakter dan Kepribadian melalui Pendidikan Kewarganegaraan. Graha Ilmu, Jakarta Branson, 